\title{
FAKTOR PEMERIKSAAN DETEKSI DINI KANKER SERVIKS METODE INSPEKSI VISUAL DENGAN ASAM ASETAT
}

\section{FACTORS FOR EARLY DETECTION OF CANCER SERVICES VISUAL INSPECTION METHOD WITH ACETIC ACID}

\author{
Netti Herawati, Enny Susilawati, Yuli Suryanti, Yasneli \\ Jurusan Kebidanan Poltekkes Kemenkes Jambi \\ Kontak Penulis: herawatinetti1974@gmail.com
}

\begin{abstract}
ABSTRAK
Penelitian ini bertujuan untuk mengetahui faktor yang berhubungan dengan pemeriksaan deteksi dini kanker serviks dengan menggunakan metode tes Inspeksi Visual dengan Asam Asetat (IVA). Penelitian ini merupakan penelitian kuantitatif dengan pendekatan crossectional untuk mengetahui faktor yang berhubungan dengan deteksi dini kanker serviks metode IVA tes di Puskesmas Kenali Besar Kota Jambi tahun 2019. Populasi penelitian ini adalah Wanita Usia Subur (WUS) yang berkunjung di Ruang KB/Kespro dari bulan Maret sampai April tahun 2019. Sampel secara quota sampling sebanyak 80 responden melalui pengisian kuisioner. Hasilnya, didapatkan $85 \%$ responden tidak melakukan IVA test, 67,5\% responden memiliki pengetahuan kurang baik, 57,5\% responden memiliki sikap kurang baik, 52,5\% responden memiliki motivasi tinggi, 56,5\% responden memiliki peran petugas baik dan $65 \%$ responden memiliki keterpaparan informasi yang baik. Didapatkan pula ada hubungan pemeriksaan skrining kanker serviks dengan pengetahuan, sikap, motivasi, peran petugas dan keterpaparan informasi. Melalui penelitian ini, diharapkan agar petugas kesehatan meningkatkan penyuluhan tentang pentingnya pemantauan kesehatan bagi WUS sebagai upaya penanggulangan dini terhadap kejadian kanker serviks.
\end{abstract}

Kata kunci: deteksi dini; kanker serviks; metode IVA test

\section{ABSTRACT}

This study aims to determine the factors associated with examinations of early detection of cervical cancer using the Visual Inspection with Acetic Acid (IVA) test method. This research is a quantitative study with a cross-sectional approach to find out the factors associated with early detection of cervical cancer IVA test methods at the Kenali Besar Health Center in Jambi City in 2019. The population of this study is Fertile Age Women (WUS) who visited the KB / Kespro Room from March until April 2019. Samples were quota sampling totaling 80 respondents through filling out questionnaires. The result, found $85 \%$ of respondents did not do the IVA test, $67.5 \%$ of respondents had poor knowledge, $57.5 \%$ of respondents had poor attitudes, $52.5 \%$ of respondents had high motivation, $56.5 \%$ of respondents had good staff roles and $65 \%$ of respondents have good information exposure. There is also a relationship between cervical cancer screening with knowledge, attitudes, motivation, the role of officers and information exposure. Through this research, it is hoped that health workers will increase awareness about the importance of health monitoring for WUS as an early response to cervical cancer.

Keywords: early detection; cervical cancer; IVA test method 


\section{PENDAHULUAN}

Hasil Riset Kesehatan Dasar tahun 2013, menyatakan bahwa prevalensi kanker serviks pada tahun 2012 di Indonesia sebesar 16 per 100.000 penduduk. Kanker serviks ini mengalami peningkatan pada tahun 2013, meningkat menjadi 17 per 100.000 (Kemenkes RI, 2013). Menurut WHO ada 4 kasus baru per menit, 1 wanita meningal per 2 menit, di Asia pasifik 1 wanita meninggal setiap 4 menit, di Indonesia 15.000 kasus pertahun dan 8000 meninggal pertahun (Syafrudin, 2011). Sementara dari Laporan Dinas Kesehatan Provinsi Jambi selama tahun 20162018 terdapat 743 kasus IVA positif dari 55.570 WUS yang diperiksa dan Kota Jambi merupakan yang terbanyak yaitu 140 kasus (Dinkes Provinsi Jambi, 2018).

Untuk mendukung program deteksi dini kanker serviks, maka diperlukan tindak lanjut pencanangan gerakan promotif, preventif dengan mendorong perempuan di setiap wilayah untuk melaksanakan deteksi dini kanker serviks (Lestari, et al, 2019). Kejadian kanker serviks dapat dicegah dengan skrining atau deteksi dini lesi prakanker. Deteksi dini lesi prakanker dapat mencegah lesi prakanker tidak berlanjut menjadi kanker leher rahim jika segera dilakukan pengobatan (Irianto, 2014,). Hal ini terbukti di negara-negara maju yang telah mengalami penurunan insiden kanker serviks. Dalam 50 tahun terakhir insidens kanker serviks turun sekitar $70 \%$ yang dimungkinkan karena adanya program deteksi dini dan tatalaksana yang baik. Hasil penelitian membuktikan bahwa deteksi dini lesi prakanker dapat menurunkan insiden kanker serviks dan menurunkan angka kematian yang disebabkan oleh kanker serviks (Mulyati et al, 2015).

Tes IVA adalah tes visual dengan menggunakan larutan asam cuka (asam asetat 3- 5\%) pada serviks dan melihat perubahan warna yang terjadi setelah dilakukan olesan. Pemeriksaan IVA adalah pemeriksaan yang pemeriksanya (dokter/bidan/perawat) mengamati serviks yang telah diberi asam asetat/asam cuka 3-5\% secara inspekulo dan dilihat dengan pengamatan mata langsung. Tujuannya untuk melihat adanya sel yang mengalami displasia sebagai salah satu metode skrining kanker serviks (Kemenkes RI, 2013).

Perilaku WUS dalam pencegahan kanker servik masih dikategorikan kurang baik seperti penelitian yang dilakukan oleh Fadilla (2012) tentang gambaran perilaku wanita usia subur tentang deteksi dini kanker serviks di poli kandungan RSUD Dr.Hardjono Ponorogo, didapatkan hasil bahwa perilaku deteksi dini kanker serviks pada pasien di poli kandungan RSUD Dr.Harjono Ponorogo masih negatif. Hal ini disebakan karena kurangnya pengetahuan tentang deteksi dini dan rendahnya kesadaran masyarakat tentang upaya pencegahan kanker serviks. Rasa takut terhadap kanker juga menyebabkan masyarakat enggan melakukan pemeriksaan (deteksi dini), menjauhkan diri dari informasi mengenai kanker, sehingga kanker terdiagnosis pada stadium lanjut (Watini \& Indrayani, 2019).

Penelitian yang dilakukan oleh Musrifah (2011) mengenai hubungan karakteristik, pengetahuan dan sikap ibu rumah tangga dengan praktik pencegahan kanker leher rahim di Kelurahan Padangsari Kecamatan Banyumanik Kota Semarang, didapatkan bahwa ada hubungan antara umur ibu rumah tangga $(\mathrm{p}=0,004)$, sikap ibu rumah tangga $(\mathrm{p}=0,033)$ dengan praktik pencegahan kanker leher rahim. Umur ibu berhubungan dengan kedewasaan dan kematangan berpikir sehingga pada usia dewasa ibu sudah sering terpapar informasi kesehatan sehingga sudah mulai menimbulkan minat untuk melakukan deteks dini. Sikap positif WUS merupaka respon atau perilaku yang masih tertutup sehingga jika sudah terbentuk dalam diri WUS akan lebih mudah diaplikasikan dalam bentuk perilaku.

Penelitian dan teori di atas menunjukkan bahwa pelaksanaan deteksi dini juga dipengaruhi oleh pengetahuan dan sikap. Sikap merupakan reaksi atau respon yang masih tertutup dari seorang terhadap suatu stimulus atau objek. Sikap secara nyata menunjukkan konotasi adanya kesesuian 
reaksi terhadap stimulus tertentu yang dalam kehidupan sehari - hari merupakan reaksi yang bersifat emosional terhadap stimulus sosial.

Kanker serviks harus ditatalaksana denganbaik, sebab jika tidak ditangani akan berdampak pada kesehatan reproduksi seseorang dan hal yang paling dikhawatirkan adalah kematian akibat kanker serviks. Dampak dari kanker serviks adalah penurunan produktifitas penderita dan pemicu stres bahkan berakibat kematian.

Program pemerintah memiliki target deteksi dini kanker serviks metode IVA sebanyak 40\% sedangkan jumlah WUS di Puskesmas Kenali Besar sebanyak 8047 orang dengan target capaian perbulan sebanyak 268 orang. Cakupan deteksi dini kanker leher rahim di puskesmas Kenali Besar masih sangat rendah. Pencapaian IVA Januari-Agustus 2018 berjumlah 184 orang dengan IVA+ sebanyak 9 orang.

Puskesmas Kenali Besar dijadikan sebagai tempat penelitian dengan berbagai pertimbangan, diantaranya cakupan wilayah kerja yang luas sehingga kemungkinan banyak masyarakat yang tidak mengakses pelayanan kesehatan karena jarak, selanjutnya jumlah WUS yang tinggi, semakin banyak jumlah WUS semakin banyak yang berisiko mengalami kanker serviks dan selanjutnya adalah masih minimnya cakupan deteksi dini kanker leher rahim di Puskesmas Kenali Besar. Berdasarkan hasil survey awal juga menunjukkan bahwa dari 5 WUS yang berkunjung ke ruang poli KB/Kespro pada tanggal 19 Januari 2019 diketahui bahwa 4 diantaranya belum pernah melakukan deteksi dini hanya 1 yang pernah melakukan skrining atau deteksi dini, saat ditanya alasan tidak melakukan deteksi dini ibu menjawab, tidak tahu program tersebut.

Berdasarkan latar belakang diatas penulis akan melakukan penelitian tentang faktor-faktor yang berhubungan dengan skrining/deteksi dini kanker serviks menggunakan metode IVA Test di Puskesmas Kenali Besar Kota Jambi tahun 2019.

\section{METODE PENELITIAN}

Penelitian ini merupakan penelitian kuantitatif dengan pendekatan crossectional untuk mengetahui faktor yang berhubungan dengan pemeriksaan deteksi dini kanker servik metode IVA Test di Puskesmas Kenali Besar Kota Jambi tahun 2019 dalam satu waktu penelitian yang meliputi pengetahuan, sikap, motivasi, peran petugas dan keterpaparan informasi.

Populasi pada penelitian ini adalah keseluruhan WUS yang berkunjung ke ruang KB/Kespro Periode Maret sampai April 2019 berjumlah 354 orang. Sampel dalam penelitian ini yaitu WUS di Puskesmas Kenali Besar yang berjumlah 80 orang dengan menggunakan rumus slovin. Pengambilan sampel dalam penelitian ini dengan menggunakan quota sampling.

Pengumpulan data dalam penelitian ini adalah menggunakan data primer yaitu data yang langsung diperoleh dari subjek yang diteliti. Pengumpulan data dilakukan dari tanggal 16 s/d 24 Mei 2019 di Puskesmas Kenali Besar Kota Jambi dengan cara pengisian kuesioner oleh responden. Peneliti dibantu oleh satu orang enumerator yang telah diberi penjelasan mengenai instumen dan cara pengumpulan data. Pengumpulan data ini menggunakan instrumen kuesioner.

Analisis univariat dilakukan terhadap tiap variabel dari hasil penelitian. Variabel yang dianalisis secara univariat dalam penelitian ini adalah pengetahuan responden. Analisis bivariat bertujuan untuk melihat hubungan variabel independent dengan variabel dependent. Uji statistik yang digunakan adalah uji chi-square. Untuk kemaknaan hasil perhitungan statistik digunakan batas kemaknaan 0,05, apabila p-value $<0,05$ artinya terdapat hubungan yang bermakna (Ho ditolak), sedangkan apabila p-value> 0,05 berarti terdapat hubungan (Ho diterima).

\section{HASIL PENELITIAN}




\section{Analisis Univariat}

1. Gambaran Pemeriksaan Deteksi Dini Kanker Serviks Metode IVA Test di Puskesmas Kenali Besar Kota Jambi Tahun 2019

Tabel 1. Distribusi Responden Menurut Pemeriksaan Deteksi Dini Kanker Serviks Metode IVA Test di Puskesmas Kenali Besar Kota Jambi Tahun 2019

\begin{tabular}{|c|c|c|}
\hline \multirow{2}{*}{$\begin{array}{c}\text { Pemeriksaan Deteksi Dini Kanker } \\
\text { Serviks Metode IVA Test }\end{array}$} & \multicolumn{2}{|c|}{ distribusi } \\
\hline & $f$ & $\%$ \\
\hline Tidak pernah & 68 & 85,0 \\
\hline Pernah & 12 & 15,0 \\
\hline Jumlah & 80 & 100,0 \\
\hline
\end{tabular}

Sumber: Data Primer 2019

Dari tabel 1 dapat dilihat bahwa sebagian besar 68 responden $(85,0 \%)$ tidak pernah melakukan pemeriksaan deteksi dini kanker serviks metode IVA Test di Puskesmas Kenali Besar Kota Jambi tahun 2019.

2. Gambaran Pengetahuan WUS tentang Pemeriksaan Deteksi Dini Kanker Serviks Metode IVA Test di Puskesmas Kenali Besar Kota Jambi Tahun 2019

Tabel 2. Distribusi Responden Menurut Pengetahuan tentang Pemeriksaan Deteksi Dini Kanker Serviks Metode IVA Test di Puskesmas Kenali Besar Kota Jambi Tahun 2019

\begin{tabular}{|c|c|c|}
\hline \multirow{2}{*}{ Pengetahuan } & \multicolumn{2}{|c|}{ Distribusi } \\
\hline & $f$ & $\%$ \\
\hline Kurang baik & 54 & 67,5 \\
\hline Baik & 26 & 32,5 \\
\hline Jumlah & 80 & 100,0 \\
\hline
\end{tabular}

Sumber: Data Primer 2019

Pada tabel 2 dapat dilihat bahwa sebagian besar 54 responden $(67,5 \%)$ mempunyai pengetahuan kurang baik tentang pemeriksaan deteksi dini kanker serviks metode IVA test di Puskesmas Kenali Besar Kota Jambi tahun 2019.

3. Gambaran Sikap WUS tentang Pemeriksaan Deteksi Dini Kanker Serviks Metode IVA Test di Puskesmas Kenali Besar Kota Jambi Tahun 2019

Tabel 3. Distribusi Responden Menurut Sikap tentang Pemeriksaan Deteksi Dini Kanker Serviks Metode IVA Test di Puskesmas Kenali Besar Kota Jambi Tahun 2019

\begin{tabular}{lccc}
\hline \multirow{2}{*}{ Sikap } & \multicolumn{2}{c}{ Distribusi } \\
\cline { 3 - 4 } & & $f$ & $\%$ \\
\hline Kurang baik & & 46 & 57,5 \\
\hline Baik & Jumlah & 34 & 42,5 \\
\hline \multicolumn{2}{c}{} & 80 & 100,0 \\
\hline
\end{tabular}

Sumber: Data Primer 2019 
Tabel 3 memperlihatkan bahwa sebagian besar 46 responden $(57,5 \%)$ mempunyai sikap kurang baik tentang pemeriksaan deteksi dini kanker serviks metode IVA test di Puskesmas Kenali Besar Kota Jambi tahun 2019.

4. Gambaran Motivasi WUS tentang Pemeriksaan Deteksi Dini Kanker Serviks Metode IVA Test di Puskesmas Kenali Besar Kota Jambi Tahun 2019

Tabel 4. Distribusi Responden Menurut Motivasi tentang Pemeriksaan Deteksi Dini Kanker Serviks Metode IVA Test di Puskesmas Kenali Besar Kota Jambi Tahun 2019

\begin{tabular}{lccc}
\hline \multirow{2}{*}{ Motivasi } & \multicolumn{2}{c}{ distribusi } \\
\cline { 3 - 4 } & & $f$ & $\%$ \\
\hline Rendah & 38 & 47,5 \\
\hline Tinggi & Jumlah & 42 & 52,5 \\
\hline & & 80 & 100,0 \\
\hline
\end{tabular}

Sumber: Data Primer 2019

Dari tabel 4 dapat dilihat bahwa sebagian besar 42 responden $(52,5 \%)$ mempunyai motivasi tinggi dalam melakukan pemeriksaan deteksi dini kanker serviks metode IVA test di Puskesmas Kenali Besar Kota Jambi tahun 2019.

5. Gambaran Peran Petugas tentang Pemeriksaan Deteksi Dini Kanker Serviks Metode IVA Test di Puskesmas Kenali Besar Kota Jambi Tahun 2019

Tabel 5. Distribusi Responden Menurut Peran Petugas tentang Pemeriksaan Deteksi Dini Kanker Serviks Metode IVA Test di Puskesmas Kenali Besar Kota Jambi Tahun 2019

\begin{tabular}{|c|c|c|}
\hline \multirow{2}{*}{ Peran Petugas } & \multicolumn{2}{|c|}{ distribusi } \\
\hline & $f$ & $\%$ \\
\hline Kurang baik & 35 & 43,8 \\
\hline Baik & 45 & 56,2 \\
\hline Jumlah & 80 & 100,0 \\
\hline
\end{tabular}

Sumber: Data Primer 2019

Pada tabel 5 dapat dilihat bahwa sebagian besar 45 responden $(56,2 \%)$ menyatakan peran petugas baik tentang pemeriksaan deteksi dini kanker serviks metode IVA test di Puskesmas Kenali Besar Kota Jambi tahun 2019.

6. Gambaran Keterpaparan Informasi WUS tentang Pemeriksaan Deteksi Dini Kanker Serviks Metode IVA Test di Puskesmas Kenali Besar Kota Jambi Tahun 2019

Tabel 6. Distribusi Responden Menurut Keterpaparan Informasi tentang Pemeriksaan Deteksi Dini Kanker Serviks Metode IVA Test di Puskesmas Kenali Besar Kota Jambi Tahun 2019 


\begin{tabular}{|c|c|c|}
\hline \multirow{2}{*}{ Keterpaparan Informasi } & \multicolumn{2}{|c|}{ distribusi } \\
\hline & $f$ & $\%$ \\
\hline Kurang baik & 28 & 35,0 \\
\hline Baik & 52 & 65,0 \\
\hline Jumlah & 80 & 100,0 \\
\hline
\end{tabular}

Sumber: Data Primer 2019

Tabel 6 memperlihatkan bahwa sebanyak 52 responden $(65,0 \%)$ mempunyai keterpaparan informasi baik tentang pemeriksaan deteksi dini kanker serviks metode IVA test di Puskesmas Kenali Besar Kota Jambi tahun 2019.

\section{Analisis Bivariat}

1. Hubungan Pengetahuan dengan Pemeriksaan Deteksi Dini Kanker Serviks Metode IVA Test di Puskesmas Kenali Besar Kota Jambi Tahun 2019

Tabel 7. Hubungan Pengetahuan dengan Pemeriksaan Deteksi Dini Kanker Serviks Metode IVA Test di Puskesmas Kenali Besar Kota Jambi Tahun 2019

\begin{tabular}{|c|c|c|c|c|c|c|c|}
\hline \multirow{3}{*}{ Pengetahuan } & \multicolumn{4}{|c|}{ Pemeriksaan IVA Test } & \multirow{2}{*}{\multicolumn{2}{|c|}{ Total }} & \multirow{3}{*}{$\begin{array}{c}\mathrm{p} \\
\text { value }\end{array}$} \\
\hline & \multicolumn{2}{|c|}{ Tidak Pernah } & \multicolumn{2}{|c|}{ Pernah } & & & \\
\hline & $f$ & $\%$ & $f$ & $\%$ & $f$ & $\%$ & \\
\hline Kurang Baik & 52 & 96,3 & 2 & 3,7 & 54 & 100,0 & \\
\hline Baik & 16 & 61,5 & 10 & 38,5 & 26 & 100,0 & 0,000 \\
\hline Jumlah & 68 & 85,0 & 12 & 15,0 & 80 & 100,0 & \\
\hline
\end{tabular}

Berdasarkan tabel 7 dilihat bahwa persentase tidak pernah melakukan pemeriksaan deteksi dini kanker serviks metode IVA tes lebih tinggi pada responden dengan pengetahuan kurang baik $(96,3 \%)$ dibanding pengetahuan baik $(61,5 \%)$. Hasil uji secara statistik antara pengetahuan dengan pemeriksaan deteksi dini kanker serviks metode IVA test diperoleh nilai $\mathrm{p}<0,05$, yang berarti ada hubungan bermakna antara pengetahuan dengan pemeriksaan deteksi dini kanker serviks metode IVA test.

2. Hubungan Sikap dengan Pemeriksaan Deteksi Dini Kanker Serviks Metode IVA Test di Puskesmas Kenali Besar Kota Jambi Tahun 2019

Tabel 8. Hubungan Sikap dengan Pemeriksaan Deteksi Dini Kanker Serviks Metode IVA Test di Puskesmas Kenali Besar Kota Jambi Tahun 2019

\begin{tabular}{|c|c|c|c|c|c|c|c|}
\hline \multirow{3}{*}{ Sikap } & \multicolumn{4}{|c|}{ Pemeriksaan IVA Test } & \multirow{2}{*}{\multicolumn{2}{|c|}{ Total }} & \multirow{3}{*}{$\underset{\text { value }}{\mathrm{p}}$} \\
\hline & \multicolumn{2}{|c|}{ Tidak Pernah } & \multicolumn{2}{|c|}{ Pernah } & & & \\
\hline & $f$ & $\%$ & $f$ & $\%$ & $f$ & $\%$ & \\
\hline Kurang Baik & 43 & 93,5 & 3 & 6,5 & 46 & 100,0 & \\
\hline Baik & 25 & 73,5 & 9 & 26,5 & 34 & 100,0 & 0,031 \\
\hline Jumlah & 68 & 85,0 & 12 & 15,0 & 80 & 100,0 & \\
\hline
\end{tabular}

Sumber: Data Primer 2019 
Tabel 8 menunjukkan bahwa persentase tidak pernah melakukan pemeriksaan deteksi dini kanker serviks metode IVA tes lebih tinggi pada responden dengan sikap kurang baik $(93,5 \%)$ dibanding sikap baik $(73,5 \%)$. Hasil uji secara statistik antara sikap dengan pemeriksaan deteksi dini kanker serviks metode IVA test diperoleh nilai $p<0,05$, yang berarti ada hubungan bermakna antara sikap dengan pemeriksaan deteksi dini kanker serviks metode IVA test.

3. Hubungan Motivasi dengan Pemeriksaan Deteksi Dini Kanker Serviks Metode IVA Test di Puskesmas Kenali Besar Kota Jambi Tahun 2019

Tabel 9. Hubungan Motivasi dengan Pemeriksaan Deteksi Dini Kanker Serviks Metode IVA Test di Puskesmas Kenali Besar Kota Jambi Tahun 2019

\begin{tabular}{|c|c|c|c|c|c|c|c|}
\hline \multirow{3}{*}{ Motivasi } & \multicolumn{4}{|c|}{ Pemeriksaan IVA Test } & \multirow{2}{*}{\multicolumn{2}{|c|}{ Total }} & \multirow{3}{*}{$\underset{\text { value }}{\mathrm{p}}$} \\
\hline & \multicolumn{2}{|c|}{ Tidak Pernah } & \multicolumn{2}{|c|}{ Pernah } & & & \\
\hline & $f$ & $\%$ & $f$ & $\%$ & $f$ & $\%$ & \\
\hline Rendah & 36 & 94,7 & 2 & 5,3 & 38 & 100,0 & \\
\hline Tinggi & 32 & 76,2 & 10 & 23,8 & 42 & 100,0 & 0,045 \\
\hline Jumlah & 68 & 85,0 & 12 & 15,0 & 80 & 100,0 & \\
\hline
\end{tabular}

Sumber: Data Primer 2019

Berdasarkan tabel 9 dilihat bahwa persentase tidak pernah melakukan pemeriksaan deteksi dini kanker serviks metode IVA tes lebih tinggi pada responden dengan motivasi rendah $(94,7 \%)$ dibanding motivasi tinggi $(76,2 \%)$. Hasil uji secara statistik antara motivasi dengan pemeriksaan deteksi dini kanker serviks metode IVA test diperoleh nilai $\mathrm{p}<0,05$, yang berarti ada hubungan bermakna antara motivasi dengan pemeriksaan deteksi dini kanker serviks metode IVA test.

4. Hubungan Peran Petugas dengan Pemeriksaan Deteksi Dini Kanker Serviks Metode IVA Test di Puskesmas Kenali Besar Kota Jambi Tahun 2019

Tabel 10. Hubungan Peran Petugas dengan Pemeriksaan Deteksi Dini Kanker Serviks Metode IVA Test di Puskesmas Kenali Besar Kota Jambi Tahun 2019

\begin{tabular}{|c|c|c|c|c|c|c|c|}
\hline \multirow{3}{*}{ Peran Petugas } & \multicolumn{4}{|c|}{ Pemeriksaan IVA Test } & \multirow{2}{*}{\multicolumn{2}{|c|}{ Total }} & \multirow{3}{*}{$\begin{array}{c}\mathrm{p} \\
\text { value }\end{array}$} \\
\hline & \multicolumn{2}{|c|}{ Tidak Pernah } & \multicolumn{2}{|c|}{ Pernah } & & & \\
\hline & $f$ & $\%$ & $f$ & $\%$ & $f$ & $\%$ & \\
\hline Kurang Baik & 34 & 97,1 & 1 & 2,9 & 35 & 100,0 & \\
\hline Baik & 34 & 75,6 & 11 & 24,4 & 45 & 100,0 & 0,018 \\
\hline Jumlah & 68 & 85,0 & 12 & 15,0 & 80 & 100,0 & \\
\hline
\end{tabular}
Sumber: Data Primer 2019

Tabel 10 menunjukkan bahwa persentase tidak pernah melakukan pemeriksaan deteksi dini kanker serviks metode IVA tes lebih tinggi pada responden dengan peran petugas kurang baik $(97,1 \%)$ dibanding peran petugas baik $(75,6 \%)$. Hasil uji secara statistik antara peran petugas dengan pemeriksaan deteksi dini kanker serviks metode IVA test diperoleh nilai $\mathrm{p}<0,05$, yang berarti ada hubungan bermakna antara peran petugas dengan pemeriksaan deteksi dini kanker serviks metode IVA test. 
5. Hubungan Keterpaparan Informasi dengan Pemeriksaan Deteksi Dini Kanker Serviks Metode IVA Test di Puskesmas Kenali Besar Kota Jambi Tahun 2019

Tabel 11. Hubungan Keterpaparan Informasi dengan Pemeriksaan Deteksi Dini Kanker Serviks Metode IVA Test di Puskesmas Kenali Besar Kota Jambi Tahun 2019

\begin{tabular}{|c|c|c|c|c|c|c|c|}
\hline \multirow{3}{*}{$\begin{array}{c}\text { Keterpaparan } \\
\text { Informasi }\end{array}$} & \multicolumn{4}{|c|}{ Pemeriksaan IVA Test } & \multirow{2}{*}{\multicolumn{2}{|c|}{ Total }} & \multirow{3}{*}{$\begin{array}{c}\mathrm{p} \\
\text { value }\end{array}$} \\
\hline & \multicolumn{2}{|c|}{ Tidak Pernah } & \multicolumn{2}{|c|}{ Pernah } & & & \\
\hline & $f$ & $\%$ & $f$ & $\%$ & $f$ & $\%$ & \\
\hline Kurang Baik & 27 & 96,4 & 1 & 3,6 & 28 & 100,0 & \\
\hline Baik & 41 & 78,8 & 11 & 21,2 & 52 & 100,0 & 0,048 \\
\hline Jumlah & 68 & 85,0 & 12 & 15,0 & 80 & 100,0 & \\
\hline
\end{tabular}

Sumber: Data Primer 2019

Berdasarkan tabel 11 dilihat bahwa persentase tidak pernah melakukan pemeriksaan deteksi dini kanker serviks metode IVA tes lebih tinggi pada responden dengan keterpaparan informasi kurang baik $(96,4 \%)$ dibanding keterpaparan informasi baik $(78,8 \%)$. Hasil uji secara statistik antara keterpaparan informasi dengan pemeriksaan deteksi dini kanker serviks metode IVA test diperoleh nilai $\mathrm{p}<0,05$, yang berarti ada hubungan bermakna antara keterpaparan informasi dengan pemeriksaan deteksi dini kanker serviks metode IVA test.

\section{PEMBAHASAN}

Tes IVA adalah tes visual dengan menggunakan larutan asam cuka (asam asetat 3-5\%) pada serviks dan melihat perubahan warna yang terjadi setelah dilakukan olesan. Pemeriksaan IVA adalah pemeriksaan yang pemeriksanya (dokter/bidan/perawat) mengamati serviks yang telah diberi asam asetat/asam cuka 3-5\% secara inspekulo dan dilihat dengan pengamatan mata langsung. Tujuannya untuk melihat adanya sel yang mengalami displasia sebagai salah satu metode skrining kanker serviks (Kemenkes RI, 2013). Sebagian besar responden tidak pernah melakukan pemeriksaan deteksi dini kanker serviks metode tes IVA. Pengetahuan dan sikap tentang tes IVA juga kurang baik meskipun sebagian besar responden menyatakan bahwa motivasi responden maupun peran petugas sudah baik sehingga sebagian besar responden mempunyai keterpaparan informasi yang baik juga. Hasil penelitian ini secara statistik menunjukkan hubungan bermakna antara sikap, motivasi, peran petugas, dan keterpaparan terhadap pemeriksaan deteksi dini kanker serviks metode tes IVA

Peran petugas baik, motivasi tinggi dan keterpaparan informasi baik sedangkan pengetahuan rendah. Oleh karena itu, untuk meningkatkan pengetahuan responden menjadi baik dan untuk meningkatkan capaian IVA Test yaitu dengan langkah-langkah menyediakan leaflet tentang kanker serviks dan pemeriksaan IVA Test. Leaflet ini disediakan di ruang tunggu, sehingga dapat dibaca saat menunggu pelayanan di Puskesmas. Selain itu juga bisa di ruangan Puskesmas ditambahkan poster tentang kanker serviks dan IVA Test yang ditempelkan di dinding, sehingga pengunjung Puskesmas dapat membacanya dengan mudah.

Responden yang mendapatkan dukungan petugas kesehatan yang baik akan cenderung melakukan pemeriksaan IVA dibanding responden yang tidak mendapatkan dukungan petugas kesehatan. Hal ini dikarenakan sebagian besar responden ditempat penelitian menganggap petugas 
kesehatan lebih banyak tahu tentang masalah kesehatan dirinya sehingga dalam pengambilan keputusan mengenai hal yang harus dilakukan tentang kesehatan lebih banyak dilibatkan

Responden yang pernah terpapar informasi mengenai pemeriksaan IVA cenderung lebih mengetahui tentang bahaya kanker serviks dan manfaat melakukan pemeriksaan IVA sehingga akan terdorong untuk melakukan pemeriksaan IVA. Sedangkan bagi responden yang tidak pernah sama sekali mendapatkan informasi mengenai pemeriksaan IVA maka akan tidak mungkin baginya untuk melakukan pemeriksaan IVA.

\section{KESIMPULAN}

Dari penelitian ini dapat diungkapkan bahwa sebagian besar responden Wanita Usia Subur (WUS) memang belum banyak melakukan uji coba tes IVA. Akantetapi peran dari petugas untuk memotivasi dan melakukan penyuluhan perlu ditingkatkan lagi agar semakin banyak WUS yang memahami dan juga tertarik untuk melakukan pencegahan kanker servik secara dini dengan metode tes IVA ini. Semakin banyak pengetahuan yang diberikan dan juga ditularkan, maka semakin baik sikap yang akan diberikan oleh WUS dalam pemeriksaan dini kanker servik menggunakan tes IVA.

\section{REFERENSI}

Dinkes Provinsi Jambi. (2018). Profil Kesehatan Provinsi Jambi tahun 2018. Jambi: Dinkes Provinsi Jambi

Fadilla. (2012). Gambaran perilaku wanita usia subur tentang deteksi dini kanker serviks di poli kandungan RSUD Dr.Hardjono Ponorogo.

Irianto, 2014. Epidemiologi Penyakit Menular \& Tidak Menular Panduan Klinis. Bandung: Alfabeta

Kemenkes RI, 2013 Riskesdas. Jakarta. Kemenkes RI

Lestari, A, I., \& Hidayat, B. (2019). Deteksi Dini Conventional Smear dan Liquid Based Cytology dalam Upaya Pencegahan Kanker Serviks: Systematic Review. Jurnal Kesehatan Reproduksi. 6(2). 71-78. https://jurnal.ugm.ac.id/jkr. DOI: 10.22146/jkr.42627

Mulyati, dkk, 2015. Pengaruh Media Film Terhadap Sikap Ibu Pada Deteksi Dini Kanker Serviks. Tersedia dalam http://journal.unnes.ac.id/nju/index.php/kemas

Musrifah, S, 2011. Hubungan karakteristik, pengetahuan dan sikap ibu rumah tangga dengan praktik pencegahan kanker leher rahim di Kelurahan Padangsari Kecamatan Banyumanik Kota Semarang.

Syafrudin, 2011. Himpunan Penyuluhan Kesehatan Pada Remaja, Keluarga, Lansia dan Masyarakat. Jakarta: Trans Info Media

Watini, N, A., \& Indrayani, N. (2019). Deteksi Dini Kanker Serviks dengan Inspeksi Visual Asam Asetat (IVA). JNK: Jurnal Ners dan Kebidanan, 6(1). 27-34. DOI:10.26699/jnk.v6i1.ART.p027-034 